\title{
Trends in Meeting the Aerobic Physical Activity Guideline Among Adults With and Without Select Chronic Health Conditions, United States, 1998-2018
}

\author{
John D. Omura, Eric T. Hyde, Giuseppina Imperatore, Fleetwood Loustalot, Louise Murphy, \\ Mary Puckett, Kathleen B. Watson, and Susan A. Carlson
}

\begin{abstract}
Background: Physical activity is central to the management and control of many chronic health conditions. The authors examined trends during the past 2 decades in the prevalence of US adults with and without select chronic health conditions who met the minimal aerobic physical activity guideline. Methods: The 1998-2018 National Health Interview Survey data were analyzed. Prevalence of meeting the minimal aerobic physical activity guideline among adults with and without 6 chronic health conditions was estimated across 3-year intervals. Linear and higher-order trends were assessed overall and by age group. Results: During the past 2 decades, prevalence of meeting the aerobic guideline increased among adults with diabetes, hypertension, coronary heart disease, stroke, cancer, and arthritis. However, the absolute increase in prevalence was lower among adults with hypertension, coronary heart disease, and arthritis compared to counterparts without each condition, respectively. Prevalence was persistently lower among those with most chronic health conditions, except cancer, and among older adults compared to their counterparts. Conclusions: Although rising trends in physical activity levels among adults with chronic health conditions are encouraging for improving chronic disease management, current prevalence remains low, particularly among older adults. Increasing physical activity should remain a priority for chronic disease management and control.
\end{abstract}

Keywords: fitness, surveillance, guidelines and recommendations

Physical activity is a cornerstone in the management and control of many chronic health conditions. ${ }^{1}$ The Physical Activity Guidelines for Americans, second edition (Guidelines) recommends that adults with chronic health conditions, who are able, should participate in at least 150 minutes a week of moderateintensity or 75 minutes a week of vigorous-intensity aerobic physical activity, or an equivalent combination of both. ${ }^{2}$ Despite efforts to promote physical activity for the management and control of chronic health conditions, physical activity levels have been historically low among adults with these conditions, particularly when compared to those without them. ${ }^{3-6}$

In addition to the health benefits of physical activity being recognized in national public health guidelines, ${ }^{2}$ multiple professional and community organizations have integrated participation in physical activity into clinical management and support through community programming. For example, the American College of Sports Medicine, American College of Cardiology, American

Omura, Hyde, Watson, and Carlson are with the Division of Nutrition, Physical Activity, and Obesity, National Center for Chronic Disease Prevention and Health Promotion, Centers for Disease Control and Prevention, Atlanta, GA, USA. Imperatore is with the Division of Diabetes Translation, National Center for Chronic Disease Prevention and Health Promotion, Centers for Disease Control and Prevention, Atlanta, GA, USA. Loustalot is with the Division for Heart Disease and Stroke Prevention, National Center for Chronic Disease Prevention and Health Promotion, Centers for Disease Control and Prevention, Atlanta, GA, USA. Murphy and Carlson are with the Division of Population Health, National Center for Chronic Disease Prevention and Health Promotion, Centers for Disease Control and Prevention, Atlanta, GA, USA. Puckett is with the Division of Cancer Prevention and Control, National Center for Chronic Disease Prevention and Health Promotion, Centers for Disease Control and Prevention, Atlanta, GA, USA. Omura (ydk8@cdc. gov) is corresponding author.
Cancer Society, American Diabetes Association, and American College of Rheumatology have recommended physical activity as part of clinical management for many chronic health conditions. ${ }^{7-11}$ To help adults with such chronic health conditions be more physically active, evidence-based, programmatic, clinical, and community interventions (eg, cardiac rehabilitation, Livestrong at the YMCA, and Walk with Ease) that include physical activity promotion have been developed specifically for adults with certain chronic health conditions. ${ }^{12-17}$ In general, such programs often tend to focus on aerobic physical activity promotion.

Previous studies assessing trends and patterns of aerobic physical activity among those with chronic health conditions have typically been cross-sectional or limited to shorter periods. ${ }^{3-6}$ Understanding longer-term trends of physical activity levels among individuals with specific chronic health conditions is important for several reasons. For example, such trends can help place changes in the context of key milestones achieved in the field of physical activity and public health during the past 2 decades, which have focused on adults with chronic health conditions, such as the release of the first federal physical activity guidelines. ${ }^{18}$ Examining trends among specific age groups, such as older adults, can help to monitor progress among populations for which relevant public health interventions are implemented, when possible, and identify opportunities to enhance interventions that are based on population-specific needs.

The National Health Interview Survey (NHIS) is a key surveillance system for monitoring national physical activity levels in the United States. ${ }^{19}$ The NHIS provides a unique opportunity to examine trends in the prevalence of meeting physical activity guidelines from 1998 to 2018; the survey methodology and the questions assessing aerobic physical activity and chronic health conditions have remained mostly unchanged during that period. 
Therefore, we used 1998-2018 NHIS data to assess trends in prevalence estimates of US adults (overall and by age group) who meet the minimal aerobic physical activity guideline among those with and without select chronic health conditions. Although the Guidelines recommend that adults with chronic conditions participate in both aerobic and muscle-strengthening physical activity, ${ }^{2}$ most programmatic interventions tend to primarily promote aerobic physical activity. As such, our study focused on aerobic physical activity although both types of activity are important. Findings can help guide efforts to increase availability and participation in clinical and community programs and interventions that promote physical activity, specifically among adults with certain chronic health conditions.

\section{Methods}

\section{Survey Design}

The NHIS is an ongoing, multistage probability sample of US households designed to be representative of the civilian, noninstitutionalized US population. The NHIS collects basic health and demographic information from all family members and additional information, such as information about leisure-time physical activity, from one randomly selected adult (aged $\geq 18$ y). From 1998 to 2018, sample sizes of sample adults ranged from 21,781 (2008) to 36,697 (2014), and response rates ranged from 53.0\% (2017) to $74.3 \%$ (2002). ${ }^{20}$ Further information about the NHIS survey is available elsewhere. ${ }^{21}$

\section{Aerobic Physical Activity}

Respondents were asked 2 series of questions that assessed how often during leisure time they participated, for 10 or more minutes at a time, in the following: (1) vigorous-intensity activities that cause heavy sweating or large increases in breathing or heart rate and (2) light- or moderate-intensity activities that cause only light sweating or slight to moderate increases in breathing or heart rate. Respondents provided both frequency of their participation (per day, week, month, or year) and duration of each session (minutes or hours). Total leisure-time physical activity was calculated as weekly minutes of moderate-intensity physical activity plus twice the reported minutes of vigorous-intensity physical activity (moderate-intensity equivalent minutes). ${ }^{2}$ Respondents were classified as meeting the minimal aerobic guideline if they reported 150 or more minutes per week of moderate-intensity equivalent physical activity. $^{2}$ Questions regarding muscle-strengthening physical activity were asked separately although they were not included in this analysis.

\section{Chronic Health Conditions}

Chronic health conditions were selected for this analysis if (1) data were available in NHIS and (2) evidence-based recommendations for physical activity as part of disease management and control have been established. In most years during 1998-2018, NHIS respondents were asked if they had ever been told by a doctor or other health professional that they had diabetes or sugar diabetes (other than during pregnancy); hypertension (also called high blood pressure); angina (also called angina pectoris); heart attack (also called myocardial infarction); coronary heart disease; stroke; cancer or a malignancy of any kind; or some form of arthritis, rheumatoid arthritis, gout, lupus, or fibromyalgia. Respondents were classified as having diabetes, hypertension, stroke, cancer, or arthritis if they responded yes to the corresponding questions for each of these conditions. Respondents were classified as having coronary heart disease if they responded yes to any of the questions regarding angina, heart attack, or coronary heart disease. The current version of the arthritis question was first consistently asked in 2001, so analyses for that condition were limited to 2001-2018.

\section{Analytic Sample}

From an initial sample of 635,580 respondents, 14,966 were removed because of missing aerobic physical activity data. Respondents with missing data for each condition (diabetes, $\mathrm{n}=9360$; hypertension, $\mathrm{n}=853$; coronary heart disease, $\mathrm{n}=1170$; stroke, $\mathrm{n}$ =620; cancer, $n=566$; and arthritis, $n=868$ ) were excluded only for condition-specific analyses. Because of sample size limitations for certain chronic health conditions, data were grouped into 3-year intervals: 1998-2000, 2001-2003, 2004-2006, 2007-2009, 2010 2012, 2013-2015, and 2016-2018.

\section{Statistical Analyses}

Our study estimated the prevalence and $95 \%$ confidence intervals of US adults with and without each of the 6 chronic health conditions, respectively (ie, diabetes, hypertension, coronary heart disease, stroke, cancer, and arthritis), who met the minimal aerobic physical activity guideline for each 3-year interval. Prevalence was estimated overall and by age category (18-34, 35-64, and $\geq 65 \mathrm{y}$ ). Overall estimates were age-standardized to the 2000 US adult population using 5 age groups (18-24, 25-34, 35-44, 45-64, and $\geq 65 \mathrm{y}$ ), whereas age-specific estimates were not. ${ }^{22}$

Significant trends in meeting guidelines were identified by using orthogonal polynomial contrasts for all chronic health conditions across intervals from 1998-2000 to 2016-2018, except for arthritis, which was examined for 2001-2003 and 2016-2018. Absolute change in meeting guidelines was calculated across all chronic health condition status and age groups as the difference in prevalence between 2016-2018 and 1998-2000 (2001-2003 for arthritis). Pairwise comparisons were used to assess whether the change in prevalence of meeting the minimal aerobic guideline between 1998-2000 (2001-2003 for arthritis) and 2016-2018 was significantly different between chronic health condition status groups (yes/no) and age groups among adults with each chronic health condition. Bonferroni adjustment was used to control for type I error for the pairwise comparisons by age group. Estimates were suppressed for subgroups with a denominator sample size of less than 250. Before Bonferroni adjustment, $P$ values less than .05 were considered statistically significant. Analyses were conducted by using SUDAAN (version 11.0; Research Triangle Institute, Research Triangle Park, NC) to account for the complex survey design and weighting and followed guidelines for combining data across years. ${ }^{20}$ This analysis was exempt from institutional review board approval because the study was considered public health surveillance, and personal identifiers were not included in the data.

\section{Results}

In 1998-2000 and 2016-2018, age-standardized prevalence of diabetes was $5.7 \%$ and $9.2 \%$, respectively (Table 1). The prevalence of hypertension was $23.1 \%$ and $28.8 \%$, coronary heart disease was $5.8 \%$ and $5.6 \%$, stroke was $2.2 \%$ and $2.8 \%$, and cancer was $6.5 \%$ and $8.4 \%$ across the same years. In 20012003 and 2016-2018, prevalence of arthritis was $21.4 \%$ and 


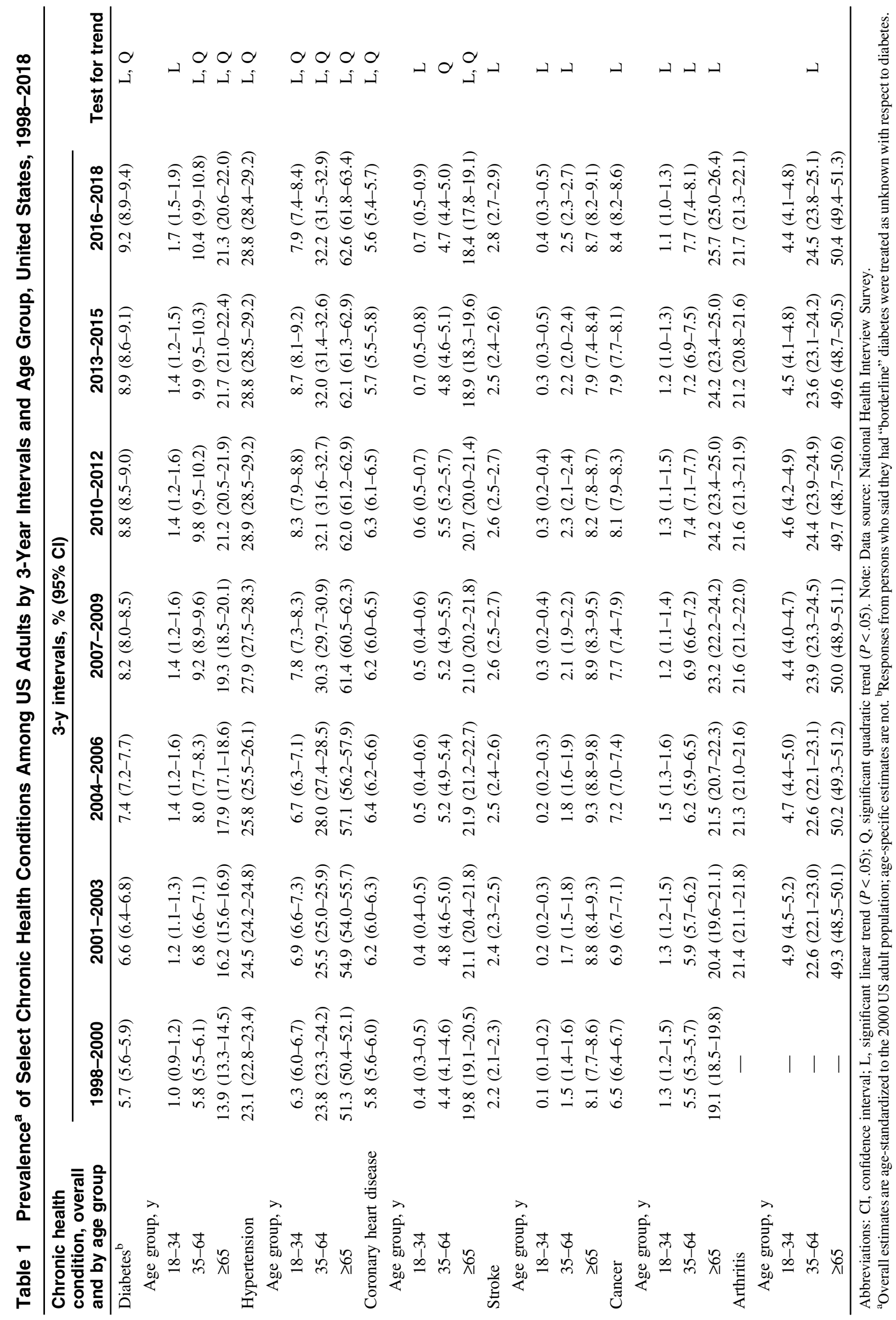


$21.7 \%$, respectively. From 1998-2000 and 2016-2018, prevalence of stroke and cancer increased linearly, and prevalence of diabetes, hypertension, and coronary heart disease increased nonlinearly. From 2001-2003 and 2016-2018, no significant trend in the prevalence of arthritis was observed. Trends across age groups were similar to trends in the overall prevalence for each chronic health condition, with some variation throughout (eg, although the prevalence of diabetes increased nonlinearly overall and among those aged 35-64 and $\geq 65 \mathrm{y}$, prevalence increased linearly among those aged 18-34 y).

In general, prevalence of meeting the minimal aerobic physical activity guideline was significantly lower among those with each condition compared to those without during most 3-year intervals, except for cancer (Figure 1, Table 2). For example, during 20162018, prevalence was lower among adults with the following chronic health conditions compared to those without: diabetes (with: 43.5\%; without: 55.1\%), hypertension (with: $47.6 \%$; without: $56.6 \%$ ), coronary heart disease (with: $39.6 \%$; without: $54.4 \%$ ), stroke (with: 41.1\%; without: 54.1), and arthritis (with: 48.9\%; without: 55.4\%). However, during 2016-2018, prevalence was similar among adults with and without cancer (with: 53.1\%; without: $53.6 \%$ ).

During the study period, prevalence of meeting the minimal aerobic physical activity guideline increased linearly among those with diabetes, hypertension, coronary heart disease, stroke, cancer, and arthritis (Figure 1, Table 2). Nonlinear trends were also present among those with hypertension and arthritis. The absolute change in prevalence of meeting the minimal aerobic physical activity guideline ranged from $6.2 \%$ among adults with coronary heart disease to $13.6 \%$ among adults with stroke. This increase was significantly lower among adults with hypertension $(P=.003)$, coronary heart disease $(P=.022)$, and arthritis $(P=.009)$ compared to those without. For example, the absolute change in prevalence of meeting the minimal aerobic physical activity guideline from 1998-2000 to 2016-2018 was lower among adults with coronary heart disease $(6.2 \%)$ compared to those without (12.8\%).

Similar patterns in trends in the prevalence of meeting the minimal aerobic physical activity guideline among adults with each chronic health condition were observed by age group, although, in general, older adults had a consistently lower prevalence of meeting the aerobic guideline than younger adults for all chronic health conditions (Table 2). For example, in 2016-2018, prevalence of meeting the aerobic guideline was lowest among adults with diabetes who were aged 65 years or older $(29.5 \%)$, followed by those who were aged $35-64$ years $(37.7 \%)$ and those who were aged 18-34 years $(55.9 \%)$. The absolute change in prevalence of meeting the minimal aerobic physical activity guideline among adults with each chronic health condition also varied by age group, although no statistically significant differences in the absolute change were observed by age group.

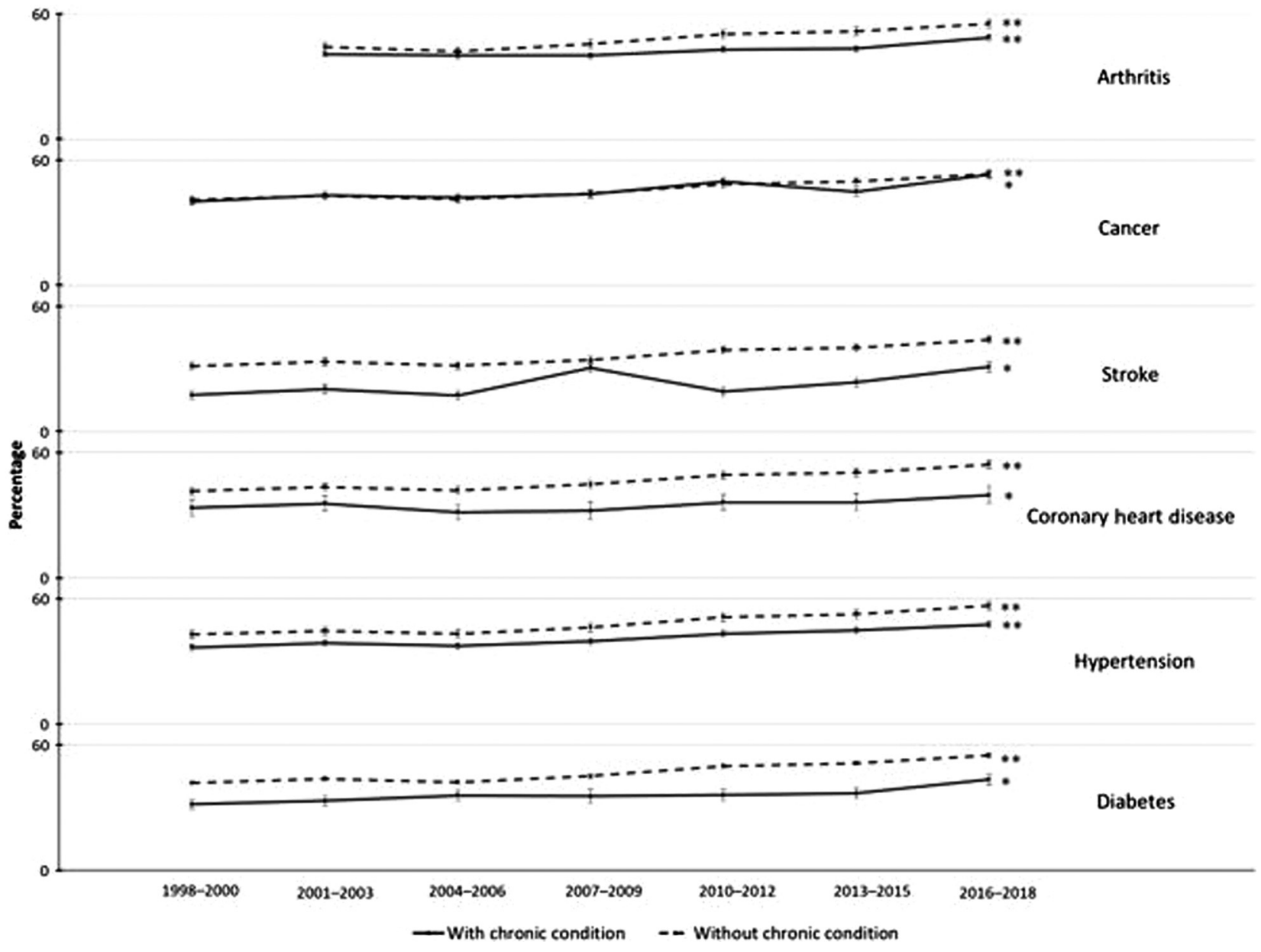

Figure 1 - Trends in meeting the minimal aerobic physical activity guideline among US adults with and without select chronic health conditions, United States, 1998-2018. Estimates are age-standardized to the 2000 US adult population. Data source: National Health Interview Survey. *Significant linear trend $(P<.05)$.**Significant linear and quadratic trends $(P<.05)$. 


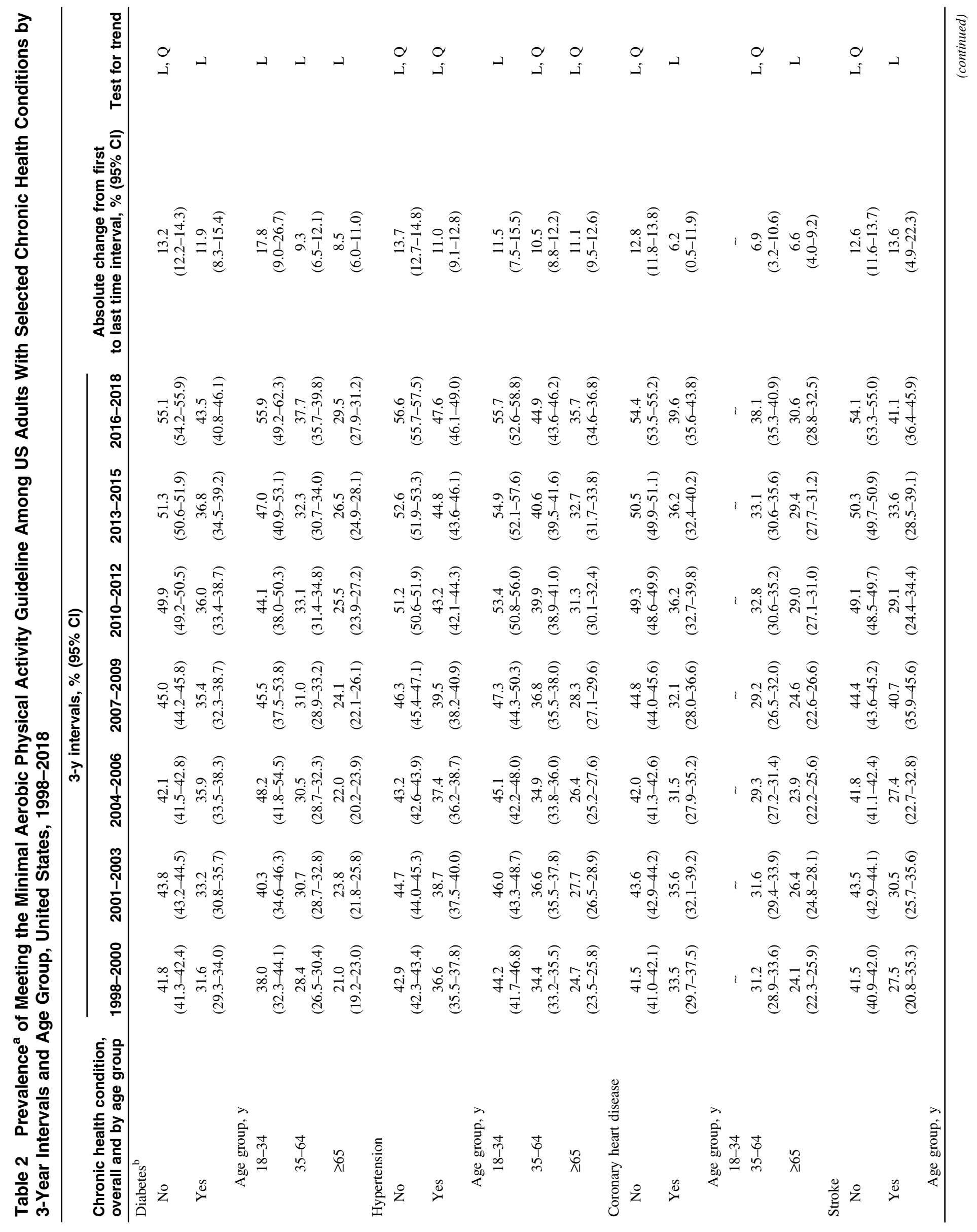




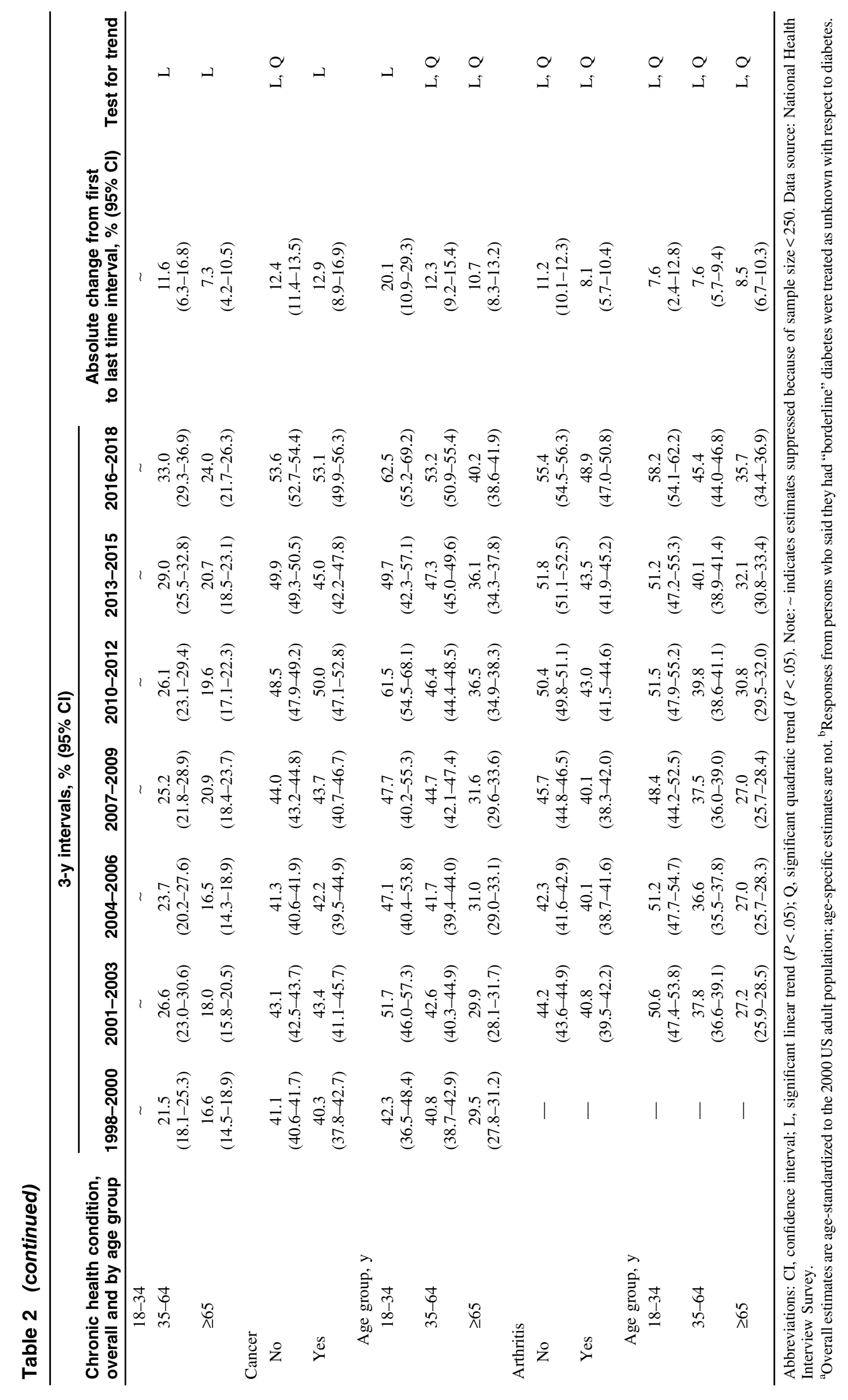




\section{Discussion}

Over the past 2 decades, the prevalence increased of meeting the minimal aerobic physical activity guideline among adults with diabetes, hypertension, coronary heart disease, stroke, cancer, and arthritis. However, this change in prevalence was lower among adults with hypertension, coronary heart disease, and arthritis compared to those without, and physical activity levels remain persistently lower among those with each chronic health condition examined compared to those without, except for cancer. Similar trends were observed among different age groups, although older adults generally had a lower prevalence of meeting the aerobic guideline than younger adults. Although the increasing trends in physical activity levels among adults with chronic health conditions are encouraging, current prevalence estimates remain low, ${ }^{23-25}$ and this is especially worrisome as the prevalence of many chronic conditions is rising. There are opportunities to promote aerobic physical activity for the management and control of several chronic health conditions and interventions that consider the unique needs of older adults.

Although previous studies have reported point estimates or short-term trends in physical activity levels among US adults with various chronic health conditions, ${ }^{3-6}$ to our knowledge, none have examined trends in estimates over a period as long as 2 decades and for this large number of chronic health conditions simultaneously. For example, a previous study examined trends in the prevalence of meeting the aerobic guideline among adults with arthritis by using NHIS data from 2008 to $2015.5^{5}$ The study found this prevalence increased significantly during these 8 years, although it was persistently lower among adults with arthritis compared to those without. ${ }^{5}$ These findings are consistent with the observations in the present study, which essentially repeated this previous analysis over a longer time. In contrast, findings for trends in aerobic physical activity participation among adults with diabetes have been mixed. For example, a study examining Behavioral Risk Factor Surveillance System data from 1996 to 2005 found that the percentage of people with diabetes who participated in physical activity did not increase over the study period, while another study examining pooled data from Behavioral Risk Factor Surveillance System, NHIS, and the National Health and Nutrition Examination Survey from 1999-2004 to 2011-2016 found that the percentage of people with diabetes who participated in $\geq 150$ minutes per week of leisure-time aerobic physical activity increased linearly over the study period. ${ }^{6,26}$ Although obesity is another important chronic health condition for which physical activity plays a key role in its prevention and control, a separate study examined trends in physical activity levels by weight status categories by using NHIS data and found that the prevalence of meeting or exceeding the aerobic guideline increased among all weight status categories from 1998 to $2018 .{ }^{27}$ Overall, our study contributes to the existing literature by examining national trends in physical activity participation among adults with chronic health conditions over 2 decades.

Several chronic health conditions related to metabolic and cardiovascular health were included in this analysis, specifically diabetes, hypertension, coronary heart disease, and stroke. Our findings suggest that although the prevalence of meeting the minimal aerobic guideline increased over time among adults with each of these chronic health conditions, the prevalence is persistently lower among those with each chronic health condition compared to those without. Similar findings among those who were overweight and had obesity are reported elsewhere. ${ }^{27,28}$ Moreover, in the present study, we observe that the change in prevalence of meeting the aerobic guideline during the past 2 decades was lower among adults with hypertension and coronary heart disease compared to those without. Taken together, these findings highlight important and ongoing opportunities to promote physical activity for chronic disease management to enhance metabolic and cardiovascular health.

To help meet these opportunities, health care providers can offer or refer adults who are overweight or have obesity, and who have known cardiovascular risk factors (including diabetes and hypertension), to behavioral counseling interventions to promote a healthful diet and physical activity, as recommended by the US Preventive Services Task Force. ${ }^{29}$ Lifestyle modification is also an integral component of management guidelines for diabetes and hypertension specifically, and data suggest that recommendations by clinicians can significantly influence patient behavior. ${ }^{8,10,30}$ The Community Preventive Services Task Force also recommends social support interventions in community settings to increase physical activity. ${ }^{31}$ Patients can be referred to promising, community-based, social support programs, such as Walk With a Doc. ${ }^{32}$

Patients with a diagnosis of heart disease or stroke may benefit from participation in the Chronic Disease Self-Management Program. ${ }^{33}$ This 6-week, community-based, self-management education program is designed to help participants gain confidence (self-efficacy) and skills to better manage their chronic health conditions, and the program has been shown to increase participation in aerobic exercise even at 9 to 12 months of follow-up. ${ }^{33} \mathrm{~A}$ similar program known as Diabetes Self-Management Education and Support is available to people with diabetes and includes physical activity as one of its 8 core content areas. ${ }^{34}$ Clinicians are also recommended to incorporate physical activity and exercise into the clinical management of patients who have had a cardiac event or stroke. ${ }^{12-15,35}$ To achieve this, patients who have had a cardiac event can be referred to cardiac rehabilitation, which is an evidence-based, comprehensive, secondary prevention program that includes supervised exercise training, education, and skills development for heart-healthy living. ${ }^{12-15,36-41}$ Yet despite the known benefits of physical activity for cardiovascular health, referral of eligible patients to lifestyle modification programs and participation in cardiac rehabilitation programs remains low. ${ }^{42-47}$ Future research can help identify effective strategies to support clinicians and the health care sector to increase the implementation and effects of clinical and community interventions to optimize the use of physical activity for metabolic and cardiovascular health.

Participation in physical activity also has a central role in cancer management and control because physical activity is known to provide many health benefits to cancer survivors. $2,7,9,48-50$ Correspondingly, physical activity promotion is included as a key component of population-wide cancer control efforts. ${ }^{9}$ Various physical activity interventions among cancer survivors have been developed and evaluated and are typically either clinic-based or home-based. ${ }^{49}$ Community-based programs have also been developed, such as Livestrong at the YMCA, a collaboration between YMCA of the United States and the Livestrong Foundation. ${ }^{16}$ This 12 -week physical activity program for cancer survivors has been shown to significantly improve physical activity levels, stamina, and quality of life among participants. ${ }^{51}$ Specifically, one study conducted among cancer survivors observed that $71 \%$ of participants randomized to the Livestrong at the YMCA program reported 150 or more minutes per week of physical activity compared to $26 \%$ of participants randomized to a control group $(P<.05){ }^{51}$ Interestingly, we observed that although the prevalence of meeting the minimal aerobic physical activity guideline increased among 
adults with cancer over the past 21 years, physical activity levels were similar between those with and without cancer. A previous study using 2005 and 2010 combined NHIS data observed that a lower percentage of cancer survivors met the aerobic physical activity guideline compared to adults without cancer. ${ }^{52}$ The differences between this observation and the present study are likely due to several differences in analytic methods, such as survey years used and inclusion/exclusion criteria. ${ }^{52}$ Future research may further examine the underlying reasons for the differences in physical activity patterns observed among adults with cancer compared to other chronic health conditions, along with the cumulative impact of co-occurring lifestyle-related chronic health conditions and corresponding relationship with physical activity. ${ }^{3,53}$

We observed that the prevalence of meeting the minimal aerobic physical activity guideline over the past 18 years increased among adults with arthritis, which is consistent with a previous trend analysis conducted over a shorter but overlapping period. ${ }^{5}$ Despite these improvements, we also observed that the change in prevalence from 2001-2003 to 2016-2018 was lower among adults with arthritis compared to those without. Several communitydelivered exercise programs that address joint pain, muscle weakness, and mobility limitations have been developed. ${ }^{17,54-57}$ Such programs have been found to reduce pain, improve physical function, and reduce depressive symptoms and anxiety among adults with arthritis and other rheumatic diseases. ${ }^{58-60}$ Individuals with arthritis may also benefit from increased aerobic exercise by participating in the Chronic Disease Self-Management Program. ${ }^{33}$ Despite these programmatic efforts and the increasing trends in physical activity participation among adults with arthritis, in 2017, physical inactivity was more prevalent among persons with severe joint pain than among those with less pain, suggesting ongoing opportunities for improvement. ${ }^{61}$

Age is an important variable to consider within this trend analysis because older adults are at higher risk of several chronic diseases and adverse outcomes, and they encounter a variety of unique barriers and motivators for physical activity participation. ${ }^{2,62,63}$ Although we observed increasing trends over time in the prevalence of meeting the aerobic guideline among adults aged 65 years or older with each chronic health condition, we also observed a persistently lower prevalence among older adults compared to younger adults. Our finding of persistently lower physical activity levels among older adults with each chronic health condition suggests that interventions intended to help older adults with chronic health conditions overcome barriers to physical activity participation may be especially impactful for chronic disease management and control. ${ }^{2}$ Although many community interventions that promote physical activity for chronic disease management have been designed specifically for older adults, future research may seek to examine ways to increase their reach and impact. ${ }^{17,54-57}$

Continued efforts to promote aerobic physical activity for the management of several chronic health conditions in the United States are needed and may be especially important because the prevalence of most chronic health conditions is also increasing. A concerted and coordinated effort to implement clinical and community interventions that include physical activity promotion and focus on adults with specific chronic health conditions can help meaningfully increase physical activity levels to better control chronic health conditions. Several national initiatives, including Active People, Healthy Nation ${ }^{\mathrm{SM}}$ and Million Hearts $®$, aim to bring together multiple sectors critical to this effort. ${ }^{64,65}$ In addition, relevant actions for specific populations and sectors are identified in key national reports, such as The Surgeon General's Call to Action to Control Hypertension and Step It Up! The Surgeon General's Call to Action to Promote Walking and Walkable Communities. ${ }^{66,67}$ In addition, access to physical activity resources for adults with specific chronic health may be particularly limited for certain groups who may encounter a variety of barriers. Future research examining underlying disparities and related barriers can help inform effective solutions and improve equity in both access to supportive resources and physical activity participation. In addition, since our study focused on aerobic physical activity, future research may seek to examine similar trends in both the prevalence of meeting the muscle-strengthening guideline alone and the aerobic and muscle-strengthening guidelines combined since both types of activity are recommended for individuals with chronic conditions. ${ }^{2}$

Our study has several limitations and strengths. In terms of limitations, the study relied on cross-sectional data, making it difficult to rule out reverse causality between chronic health condition status and physical activity levels, as well as self-reported data, which are subject to recall, diagnosis, and social desirability biases. ${ }^{68}$ In addition, the NHIS asks respondents to report aerobic activity that occurred in bouts of at least 10 minutes. ${ }^{21}$ Although the 2008 Physical Activity Guidelines for Americans included a bout minimum of at least 10 minutes for the adult aerobic physical activity guideline, this requirement was removed in the second edition of the guidelines. ${ }^{2,18}$ However, data suggest that eliminating the 10-minute bout minimum may have little effect on physical activity estimates. ${ }^{69}$ This study's primary strength lies in its analysis of 21 consecutive years of consistent NHIS physical activity data, which allows for examination of trends in meeting physical activity guidelines across 2 decades among age groups with a variety of chronic health conditions for which physical activity is an important modifiable behavior for disease management and control.

\section{Conclusions}

Although rising trends in physical activity levels among adults with chronic health conditions during the past 2 decades are encouraging for improving chronic disease management, current prevalence remains low, particularly among older adults. Increasing physical activity should remain a priority for chronic disease management and control.

\section{Acknowledgments}

The findings and conclusions in this report are those of the authors and do not necessarily represent the official position of the Centers for Disease Control and Prevention.

\section{References}

1. Physical Activity Guidelines Advisory Committee. 2018 Physical Activity Guidelines Advisory Committee Scientific Report. 2018; Washington, DC: Author.

2. U.S. Department of Health and Human Services. Physical Activity Guidelines for Americans. 2nd ed. Washington, DC: U.S. Government Printing Office; 2018.

3. Brawner CA, Churilla JR, Keteyian SJ. Prevalence of physical activity is lower among individuals with chronic disease. Med Sci Sports Exerc. 2016;48(6):1062-1067. PubMed ID: 26741117 doi:10. 1249/MSS.0000000000000861 
4. Steeves JA, Murphy RA, Crainiceanu CM, Zipunnikov V, Van Domelen DR, Harris TB. Daily patterns of physical activity by type 2 diabetes definition: comparing diabetes, prediabetes, and participants with normal glucose levels in NHANES 2003-2006. Prev Med Rep. 2015;2:152-157. doi:10.1016/j.pmedr.2015.02.007

5. Murphy LB, Hootman JM, Boring MA, et al. Leisure time physical activity among U.S. adults with arthritis, 2008-2015. Am J Prev Med. 2017;53(3):345-354. doi:10.1016/j.amepre.2017.03.017

6. Zhao G, Ford ES, Li C, Mokdad AH. Compliance with physical activity recommendations in US adults with diabetes. Diabet Med. 2008;25(2):221-227. PubMed ID: 18201213 doi:10.1111/j.14645491.2007.02332.x

7. Schmitz KH, Courneya KS, Matthews C, et al. American College of Sports Medicine roundtable on exercise guidelines for cancer survivors. Med Sci Sports Exerc. 2010;42(7):1409-1426. PubMed ID: 20559064 doi:10.1249/MSS.0b013e3181eec112

8. Whelton PK, Carey RM, Aronow WS, et al. 2017 ACC/AHA/AAPA/ ABC/ACPM/AGS/APhA/ASH/ASPC/NMA/PCNA guideline for the prevention, detection, evaluation, and management of high blood pressure in adults: a report of the American College of Cardiology/ American Heart Association task force on clinical practice guidelines. J Am Coll Cardiol. 2018;71(19):e127-e248. doi:10.1016/j.jacc.2017. 11.006

9. Rock CL, Doyle C, Demark-Wahnefried W, et al. Nutrition and physical activity guidelines for cancer survivors. CA Cancer J Clin. 2012;62(4):242-274. PubMed ID: 22539238 doi:10.3322/caac.21142

10. American Diabetes Association. 5 facilitating behavior change and well-being to improve health outcomes: standards of medical care in diabetes-2020. Diabetes Care. 2020;43(suppl 1):S48-S65. doi:10. 2337/dc20-s005

11. Kolasinski SL, Neogi T, Hochberg MC, et al. 2019 American College of Rheumatology/Arthritis Foundation guideline for the management of osteoarthritis of the hand, hip, and knee. Arthritis Rheumatol. 2020;72(2):220-233. doi:10.1002/art.41142

12. Taylor RS, Brown A, Ebrahim S, et al. Exercise-based rehabilitation for patients with coronary heart disease: systematic review and metaanalysis of randomized controlled trials. Am J Med. 2004;116(10): 682-692. doi:10.1016/j.amjmed.2004.01.009

13. Anderson L, Thompson DR, Oldridge N, et al. Exercise-based cardiac rehabilitation for coronary heart disease. Cochrane Database Syst Rev. 2016;(1):CD001800. doi:10.1002/14651858.cd001800.pub3

14. Rejeski WJ, Foy CG, Brawley LR, et al. Older adults in cardiac rehabilitation: a new strategy for enhancing physical function. Med Sci Sports Exerc. 2002;34(11):1705-1713. PubMed ID: 12439072 doi:10.1097/00005768-200211000-00003

15. Oldridge N, Streiner D, Hoffmann R, Guyatt G. Profile of mood states and cardiac rehabilitation after acute myocardial infarction. Med Sci Sports Exerc. 1995;27(6):900-905. PubMed ID: 7658953 doi:10. 1249/00005768-199506000-00016

16. Livestrong at the YMCA. https://www.livestrong.org/what-we-do/ program/livestrong-at-the-ymca. Accessed October 22, 2020.

17. Walk with Ease. https://www.arthritis.org/health-wellness/healthyliving/physical-activity/walking/walk-with-ease. Accessed October 20, 2020.

18. U.S. Department of Health and Human Services. 2008 Physical Activity Guidelines for Americans. Washington, DC: U.S. Government Printing Office; 2008.

19. Omura JD. PLACE HOLDER: history and opportunities for physical activity and sedentary behavior surveillance in youth and adults; 2021.

20. National Center for Health Statistics. Survey description, national health interview survey, 2018. 2019. Hyattsville, MD.
21. National Health Interview Survey. https://www.cdc.gov/nchs/nhis/ index.htm. Accessed October 20, 2020.

22. Klein RJ, Schoenborn CA. Age adjustment using the 2000 projected U.S. population. Healthy People 2010 Stat Notes, no. 20. Hyattsville, MD: National Center for Health Statistics.

23. U.S. Department of Health and Human Services. Healthy people 2030. https://health.gov/healthypeople. Accessed October 26, 2020.

24. Fulton JE, Buchner DM, Carlson SA, et al. CDC's Active People, Healthy Nation $^{\text {SM }}$ : creating an active America, together. $J$ Phys Act Health. 2018;15(7):469. PubMed ID: 29932005 doi:10.1123/jpah. 2018-0249

25. Wall HK, Ritchey MD, Gillespie C, Omura JD, Jamal A, George MG. Vital signs: prevalence of key cardiovascular disease risk factors for million hearts 2022-United States, 2011-2016. MMWR Morb Mortal Wkly Rep. 2018;67(35):983-991. PubMed ID: 30188885 doi:10. 15585/mmwr.mm6735a4

26. Fang M. Trends in diabetes management among US adults: 19992016. J Gen Intern Med. 2020;35(5):1427-1434. PubMed ID: 31898135 doi:10.1007/s11606-019-05587-2

27. Whitfield GP, Hyde ET, Carlson SA. Participation in leisure-time aerobic physical activity among adults, National Health Interview Survey, 1998-2018. J Phys Act Health. 2021;18(suppl):S25-S36. doi:10.1123/jpah.2021-0014

28. Carlson SA, Fulton JE, Pratt M, Yang Z, Adams EK. Inadequate physical activity and health care expenditures in the United States. Prog Cardiovasc Dis. 2015;57(4):315-323. PubMed ID: 25559060 doi:10.1016/j.pcad.2014.08.002

29. LeFevre ML. U.S. preventive services task force. Behavioral counseling to promote a healthful diet and physical activity for cardiovascular disease prevention in adults with cardiovascular risk factors: U.S. Preventive Services Task Force Recommendation Statement. Ann Intern Med. 2014;161(8):587-593. doi:10.7326/m14-1796

30. Yang K, Lee YS, Chasens ER. Outcomes of health care providers' recommendations for healthy lifestyle among U.S. adults with prediabetes. Metab Syndr Relat Disord. 2011;9(3):231-237. PubMed ID: 21361822 doi:10.1089/met.2010.0112

31. Kahn EB, Ramsey LT, Brownson RC, et al. The effectiveness of interventions to increase physical activity. A systematic review. Am J Prev Med. 2002;22(4):73-107. doi:10.1016/S0749-3797(02)00434-8

32. Walk with a Doc. https://walkwithadoc.org/. Accessed October 20, 2020.

33. Brady TJ, Murphy L, O'Colmain BJ, et al. A meta-analysis of health status, health behaviors, and health care utilization outcomes of the Chronic Disease Self-Management Program. Prev Chronic Dis. 2013;10:120112. PubMed ID: 23327828 doi:10.5888/pcd10.120112

34. Beck J, Greenwood DA, Blanton L, et al. 2017 national standards for diabetes self-management education and support. Diabetes Care. 2017;40(10):1409-1419. PubMed ID: 28754780 doi:10.2337/dci17-0025

35. Billinger SA, Arena R, Bernhardt J, et al. Physical activity and exercise recommendations for stroke survivors: a statement for healthcare professionals from the American Heart Association/American Stroke Association. Stroke. 2014;45(8):2532-2553. PubMed ID: 24846875 doi:10.1161/STR.0000000000000022

36. Smith SC Jr, Benjamin EJ, Bonow RO, et al. AHA/ACCF secondary prevention and risk reduction therapy for patients with coronary and other atherosclerotic vascular disease: 2011 update: a guideline from the American Heart Association and American College of Cardiology Foundation endorsed by the World Heart Federation and the Preventive Cardiovascular Nurses Association. J Am Coll Cardiol. 2011; 58(23):2432-2446. PubMed ID: 22055990 doi:10.1016/j.jacc.2011. 10.824 
37. Anderson JL, Adams CD, Antman EM, et al. ACC/AHA 2007 guidelines for the management of patients with unstable angina/ non-ST-Elevation myocardial infarction: a report of the American College of Cardiology/American Heart Association task force on practice guidelines (writing committee to revise the 2002 guidelines for the management of patients with unstable angina/non-ST-elevation myocardial infarction) developed in collaboration with the American College of Emergency Physicians, the society for cardiovascular angiography and interventions, and the society of thoracic surgeons endorsed by the American Association of Cardiovascular and Pulmonary Rehabilitation and the Society for Academic Emergency Medicine. J Am Coll Cardiol. 2007;50(7):e1-e157. PubMed ID: 17692738 doi:10.1016/j.jacc.2007.02.013

38. Levine GN, Bates ER, Blankenship JC, et al. 2011 ACCF/AHA/ SCAI guideline for percutaneous coronary intervention. A report of the American College of Cardiology Foundation/American Heart Association task force on practice guidelines and the society for cardiovascular angiography and interventions. J Am Coll Cardiol. 2011;58(24):e44-e122. PubMed ID: 22070834 doi:10.1016/j.jacc. 2011.08.007

39. Yancy CW, Jessup M, Bozkurt B, et al. 2013 ACCF/AHA guideline for the management of heart failure: a report of the American College of Cardiology Foundation/American Heart Association Task Force on Practice Guidelines. J Am Coll Cardiol. 2013;62(16):e147-e239. PubMed ID: 23747642 doi:10.1016/j.jacc.2013.05.019

40. Eagle KA, Guyton RA, Davidoff R, et al. ACC/AHA 2004 guideline update for coronary artery bypass graft surgery: summary article. A report of the American College of Cardiology/American Heart Association Task Force on Practice Guidelines (Committee to Update the 1999 Guidelines for Coronary Artery Bypass Graft Surgery). J Am Coll Cardiol. 2004;44(5):e213-e310. doi:10.1016/j.jacc.2004.07.021

41. Sibilitz KL, Berg SK, Tang LH, et al. Exercise-based cardiac rehabilitation for adults after heart valve surgery. Cochrane Database Syst Rev. 2016;3:CD010876. doi:10.1002/14651858.cd010876.pub2

42. Suaya JA, Shepard DS, Normand SL, Ades PA, Prottas J, Stason WB. Use of cardiac rehabilitation by Medicare beneficiaries after myocardial infarction or coronary bypass surgery. Circulation. 2007;116(15):1653-1662. PubMed ID: 17893274 doi:10.1161/ CIRCULATIONAHA.107.701466

43. Fang J, Ayala C, Luncheon C, Ritchey M, Loustalot F. Use of outpatient cardiac rehabilitation among heart attack survivors-20 states and the district of Columbia, 2013 and four states, 2015. MMWR Morb Mortal Wkly Rep. 2017;66(33):869-873. PubMed ID: 28837549 doi:10.15585/mmwr.mm6633a1

44. Park LG, Schopfer DW, Zhang N, Shen H, Whooley MA. Participation in cardiac rehabilitation among patients with heart failure. J Card Fail. 2017;23(5):427-431. PubMed ID: 28232047 doi:10.1016/j. cardfail.2017.02.003

45. Beatty AL, Truong M, Schopfer DW, Shen H, Bachmann JM, Whooley MA. Geographic variation in cardiac rehabilitation participation in Medicare and veterans affairs populations: opportunity for improvement. Circulation. 2018;137(18):1899-1908. PubMed ID: 29305529 doi:10.1161/CIRCULATIONAHA.117.029471

46. Bachmann JM, Shah AS, Duncan MS, et al. Cardiac rehabilitation and readmissions after heart transplantation. J Heart Lung Transplant. 2018;37(4):467-476. PubMed ID: 28619383 doi:10.1016/j. healun.2017.05.017

47. Omura JD, Bellissimo MP, Watson KB, Loustalot F, Fulton JE, Carlson SA. Primary care providers' physical activity counseling and referral practices and barriers for cardiovascular disease prevention. Prev Med. 2018;108:115-122. PubMed ID: 29288783 doi:10.1016/j. ypmed.2017.12.030
48. McTiernan A, Friedenreich CM, Katzmarzyk PT, et al. Physical activity in cancer prevention and survival: a systematic review. Med Sci Sports Exerc. 2019;51(6):1252-1261. PubMed ID: 31095082 doi:10.1249/MSS.0000000000001937

49. Demark-Wahnefried W, Schmitz KH, Alfano CM, et al. Weight management and physical activity throughout the cancer care continuum. CA Cancer J Clin. 2018;68(1):64-89. PubMed ID: 29165798 doi:10.3322/caac. 21441

50. Moore SC, Lee IM, Weiderpass E, et al. Association of leisure-time physical activity with risk of 26 types of cancer in 1.44 million adults. JAMA. 2016;176(6):816-825. doi:10.1001/jamainternmed.2016. 1548

51. Irwin ML, Cartmel B, Harrigan M, et al. Effect of the LIVESTRONG at the YMCA exercise program on physical activity, fitness, quality of life, and fatigue in cancer survivors. Cancer. 2017;123(7):12491258. PubMed ID: 27893938 doi:10.1002/cncr.30456

52. Tarasenko YN, Miller EA, Chen C, Schoenberg NE. Physical activity levels and counseling by health care providers in cancer survivors. Prev Med. 2017;99:211-217. PubMed ID: 28131780 doi:10.1016/j. ypmed.2017.01.010

53. Ford ES, Croft JB, Posner SF, Goodman RA, Giles WH. Co-occurrence of leading lifestyle-related chronic conditions among adults in the United States, 2002-2009. Prev Chronic Dis. 2013;10:E60. doi: $10.5888 /$ pcd 10.120316

54. Arthritis Foundation Aquatic Program. 2020. https://www.cdc.gov/ arthritis/interventions/programs/afap.htm. Accessed October 20, 2020.

55. Active Living Every Day. https://www.cdc.gov/arthritis/interventions/ programs/aled.htm. Accessed October 20, 2020.

56. EnhanceFitness ${ }^{\circledR}$. https://projectenhance.org/EnhanceFitness.aspx. Accessed October 20, 2020

57. Fit \& Strong! https://www.cdc.gov/arthritis/interventions/programs/ fit-strong.htm. Accessed October 20, 2020.

58. Kelley GA, Kelley KS, Hootman JM, Jones DL. Effects of community-deliverable exercise on pain and physical function in adults with arthritis and other rheumatic diseases: a meta-analysis. Arthritis Care Res. 2011;63(1):79-93. doi:10.1002/acr.20347

59. Kelley GA, Kelley KS, Hootman JM. Effects of exercise on depression in adults with arthritis: a systematic review with meta-analysis of randomized controlled trials. Arthritis Res Ther. 2015;17(1):21. PubMed ID: 25645739 doi:10.1186/s13075-015-0533-5

60. Kelley GA, Kelley KS, Callahan LF. Community-deliverable exercise and anxiety in adults with arthritis and other rheumatic diseases: a systematic review with meta-analysis of randomised controlled trials. BMJ Open. 2018;8(2):e019138. doi:10.1136/ bmjopen-2017-019138

61. Guglielmo D, Murphy LB, Boring MA, et al. State-specific severe joint pain and physical inactivity among adults with arthritis-United States, 2017. MMWR Morb Mortal Wkly Rep. 2019;68(17):381-387. doi:10.15585/mmwr.mm6817a2

62. Centers for Disease Control and Prevention. Promoting health for older adults. 2020. https://www.cdc.gov/chronicdisease/resources/ publications/factsheets/promoting-health-for-older-adults.htm. Accessed October 30, 2020.

63. Spiteri K, Broom D, Bekhet AH, de Caro JX, Laventure B, Grafton $\mathrm{K}$. Barriers and motivators of physical activity participation in middle-aged and older-adults - a systematic review. J Aging Phys Act. 2019;27(6):929-944. PubMed ID: 31141447 doi:10.1123/japa. 2018-0343

64. Active People, Healthy Nation ${ }^{\text {sM }}$. 2021. https://www.cdc. gov/physicalactivity/activepeoplehealthynation/index.html. Accessed October 22, 2020. 
65. Million Hearts®. 2021. https://millionhearts.hhs.gov/. Accessed October 22, 2020.

66. U.S. Department of Health and Human Services. The surgeon general's call to action control hypertension. Washington, DC: U.S. Department of Health and Human Services, Office of the Surgeon General; 2020.

67. U.S. Department of Health and Human Services. Step It Up! The surgeon general's call to action to promote walking and walkable communities. Washington, DC: U.S. Dept of Health and Human Services, Office of the Surgeon General; 2015.
68. Rzewnicki R, Vanden Auweele Y, De Bourdeaudhuij I. Addressing overreporting on the International Physical Activity Questionnaire (IPAQ) telephone survey with a population sample. Public Health Nutr. 2003;6(3):299-305. PubMed ID: 12740079 doi:10.1079/ PHN2002427

69. Ussery EN, Watson KB, Carlson SA. The influence of removing the ten-minute bout requirement on national physical activity estimates. Prev Chronic Dis. 2020;17:E19. PubMed ID: 32105588 doi:10.5888/ pcd17.190321 